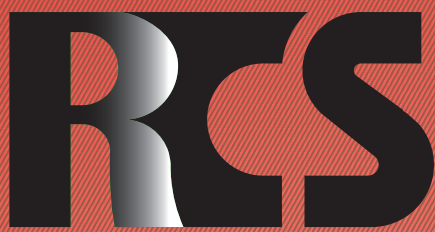

Depósito legal ppi $201502 Z U 4662$

Esta publicación científica en formato digital es continuidad de la revista impresa Depósito Legal: pp $197402 Z$ U789

- ISSN: 1315-9518 • ISSN-E: 2477-9431

Revista de Ciencias Sociales

Universidad del Zulia. Revista de la Facultad de Ciencias Económicas y Sociales Vol. XXVII,

No. 4,2021

Esta publicación científica en formato digital es continuidad de la revista impresa Depósito Legal: pp $197402 Z U 789$ ISSN: $1315-9518$ 
Como citar APA: Álvarez-Maldonado, D., Torres-Luque, P., Letzkus-Palavecino, M., y Araya-Castillo, L. (2021). Mapa de consenso del bienestar de inmigrantes en Lo Prado en Santiago de Chile. Revista de Ciencias Sociales (Ve), XXVII(4), 387-401.

\title{
Mapa de consenso del bienestar de inmigrantes en Lo Prado en Santiago de Chile
}

\author{
Álvarez-Maldonado, David* \\ Torres-Luque, Patricio ${ }^{* *}$ \\ Letzkus-Palavecino, Manuel ${ }^{* * *}$ \\ Araya-Castillo, Luis ${ }^{* * * *}$
}

\section{Resumen}

La migración es de relevancia para las autoridades de la comuna de Lo Prado en Santiago de Chile, enfrentándose al problema de diseñar servicios locales que aborden la población inmigrante con el requerimiento de conocer a las personas usuarias de prestaciones públicas. El objetivo del trabajo es describir las subjetividades asociadas al bienestar de la población inmigrante local beneficiaria de servicios municipales en un mapa de consenso que representa sus características comunes, mediante el análisis de la información entregada por una muestra de doce informantes clave, selección por conveniencia dirigida por las autoridades de la comuna Lo Prado. Se desarrolla una metodología de investigación inductiva y empírica, con enfoque cualitativo de alcance descriptivo, que aplica técnicas del marketing, recolectando datos mediante entrevistas semiestructuradas en profundidad, basadas en procedimientos proyectivos sobre imágenes y dibujos, con el propósito de responder a la pregunta sobre las características subjetivas de la población inmigrante. Los resultados evidencian la centralidad de temáticas sobre la obtención de ingresos económicos y la satisfacción de necesidades básicas en el marco de actividades familiares y de emprendimiento. Se concluye, que existen necesidades básicas no cubiertas asociadas a la relevancia de diseñar servicios públicos pertinentes.

Palabras clave: Bienestar; inmigrantes; mapa de consenso; Lo Prado; Chile.

\footnotetext{
Magíster en Dirección Estratégica de Recursos Humanos y Comportamiento Organizacional. Antropólogo Social. Profesor Asistente Adjunto de la Universidad Tecnológica Metropolitana de Chile. E-mail: d.alvarez.maldonado@gmail.com iD ORCID: https://orcid.org/0000-0002-6375-0461

** Magíster en Planificación y Gestión de Nuevos Productos y Destinos Turísticos. Docente Asistente de la Universidad Tecnológica Metropolitana, Chile. E-mail: ptorres@utem.cl (iD) ORCID: https://orcid. org/0000-0002-8193-0423

*** Doctor en Ciencias Logísticas y Supply Chain Management. Máster en Dirección y Administración de Empresas. Profesor Asociado de la Universidad Tecnológica Metropolitana, Chile. E-mail: mletzkus@ utem.cl (iD) ORCID: https://orcid.org/0000-0003-1984-8899

**** $\mathrm{PhD}$. in Management Sciences. Doctor en Ciencias de la Gestión. Doctor en Empresa. Profesor

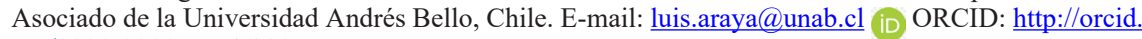
org/0000-0001-7574-3907
}

Recibido: 2021-06-14 · Aceptado: 2021-08-29 


\title{
Consensus map of the well-being of immigrants in Lo Prado in Santiago de Chile
}

\begin{abstract}
Migration is of relevance for the authorities of the Lo Prado commune in Santiago de Chile, facing the problem of designing local services that address the immigrant population with the requirement of knowing the users of public benefits. The objective of the work is to describe the subjectivities associated with the well-being of the local immigrant population benefiting from municipal services in a consensus map that represents their common characteristics, through the analysis of the information provided by a sample of twelve key informants, selection by targeted convenience. by the authorities of the Lo Prado commune. An inductive and empirical research methodology is developed, with a qualitative approach of descriptive scope, which applies marketing techniques, collecting data through in-depth semi-structured interviews, based on projective procedures on images and drawings, in order to answer the question about the subjective characteristics of the immigrant population. The results show the centrality of issues on obtaining economic income and the satisfaction of basic needs in the framework of family and entrepreneurial activities. It is concluded that there are basic unmet needs associated with the relevance of designing relevant public services.
\end{abstract}

Keywords: Well-being; immigrants; consensus map; Lo Prado; Chile., Immigrants, Lo Prado, Chile.

\section{Introducción}

El crecimiento económico de las últimas décadas, a nivel global, no garantiza un aumento en la satisfacción de la ciudadanía en general; junto a esto, el estudio del bienestar subjetivo de los países tiene una relevancia contemporánea que contrasta con la larga tradición académica ocupada en investigar la causa de la riqueza de las naciones (Sánchez, 2006; Ucak, 2015).

La variabilidad del bienestar subjetivo en la población no se encuentra necesariamente vinculada con los ingresos de las personas; por ejemplo, desde 1946 a 1970 en EE.UU. aumentaron significativamente el ingreso de los individuos, sin embargo, el bienestar no evidenció grandes cambios, e incluso disminuyó llegando a la década de los setenta (Easterlin, 1974), mientras que en países de menos ingresos y economías más pequeñas como Bután, se promueve la felicidad como política de gobierno mediante el Índice de Felicidad Nacional Bruta (Adler, 2009), repercutiendo positivamente en una evaluación del bienestar subjetivo.
En este marco contextual sobre la problemática del bienestar subjetivo de la población, se ha derivado el constructo " $\mathrm{La}$ economía de la felicidad" (Graham, 2005, p.41), el cual es un planteamiento para evaluar el bienestar, utilizando las técnicas elaboradas por economistas y psicólogos, en función de las evidencias recopiladas en encuestas sobre la felicidad en diferentes países, asociándose positivamente con varios resultados deseables, como el éxito, la larga vida, la paz, la democracia, el progreso económico y los comportamientos prosociales, entre otros (Lyubomirsky, King y Diener, 2005; Oishi y Schimmack, 2010).

El informe de la Comisión para la Medición del Desempeño Económico y el Progreso Social de la Organisation for Economic Co-operation and Development (OCDE, 2013), ha publicado directrices detalladas sobre la medición del bienestar subjetivo, siendo una de estas el Índice de Better Life, el cual es una herramienta interactiva que permite al usuario comparar el desempeño de los países en función de sus propias preferencias en relación con otros once 
factores, como vivienda, educación e ingresos, entre otros.

Junto a esto, en el año 2011 la Asamblea General de las Naciones Unidas (United Nations, 2011) aprobó una resolución sobre la felicidad desde un enfoque holístico, sosteniendo que la búsqueda de la felicidad es un objetivo humano fundamental, reconociendo, además, que el indicador del producto interno bruto no fue diseñado para tales efectos, y en consecuencia no reflejaba eficazmente el bienestar de las personas de un país.

Un año después se publicó el primer informe sobre la felicidad mundial, por medio de la Red de Soluciones para el Desarrollo Sostenible de las Naciones Unidas, incluyendo un ranking de países sobre el índice de su felicidad o bienestar subjetivo (Helliwell et al., 2012; 2015; 2018; 2019; 2020). En estos informes se ha logrado observar cómo varía el bienestar subjetivo en todo el mundo, según sexo, edad, origen migratorio, entre otros, destacando variables como la percepción de control de la propia vida o de la libertad de elección (Helliwell et al., 2015; Minkov y Bond, 2017).

En el marco conceptual de la perspectiva sobre la variabilidad del bienestar subjetivo documentado por diferentes organismos internacionales, los antecedentes validan entender el bienestar de la población como un fenómeno multicausal, el cual no está mecánicamente relacionado con los ingresos económicos, resultando en una particularidad contingente cada variabilidad subjetiva presente en grupos de personas.

El presente estudio tiene por objetivo describir las características del bienestar subjetivo específico del inmigrante de la Comuna de Lo Prado de Santiago de Chile, mediante el análisis cualitativo de una muestra de doce informantes clave, dirigida y seleccionada por conveniencia según criterios e intereses del gobierno local, según el trabajo de campo realizado por sus funcionarios municipales, y en función de la participación de las personas inmigrantes en los servicios municipales. Este procedimiento de enfoque cualitativo, desarrollado mediante técnicas del marketing, fue orientado por las autoridades de la comuna, para responder la pregunta sobre: ¿Cuáles son las características del bienestar subjetivo de la población inmigrante que utiliza servicios municipales de la Comuna de Lo Prado de Santiago de Chile?

\section{Fundamentación teórica}

\subsection{Costos de la migración}

En la actualidad, las personas y las organizaciones tienen la capacidad para transferir recursos y movilizarse con un alcance global, interconectando culturas debido a fenómenos migratorios relacionados a la necesidad bienestar (Ghorra-Gobin, 2006; Ottonelli y Torresi, 2013; Torres, 2019); sin embargo, existen costos que el inmigrante padece al dejar su tierra natal, debido a las barreras de entrada para la inclusión social producto de diferencias lingüísticas y culturales, resultando en aislamiento social y dificultades de apoyo (Morosanu, 2013).

La inmigración implica una posición más baja en la jerarquía social, un sentido de subalternidad social y estrés por la adaptación cultural (Berry, 2006). Por otra parte, respecto de la relación costos-beneficios (Frey y Stutzer, 2014), y de la ambivalencia en la ganancia de felicidad del inmigrante, sucede que tiende a adaptarse mejor a los beneficios típicos de la inmigración, como el seguro social y el beneficio económico, en comparación a sus costos, como la lejanía de la familia y la soledad. Junto a esto, el inmigrante, sacrifica parte de las ganancias económicas obtenidas, puesto que éste envía remesas a sus países de origen.

De acuerdo con Ratha, Eigen-Zucchi y Plaza (2016), las remesas enviadas por inmigrantes a sus países de origen superaron los US\$ 600 mil millones a nivel mundial, de lo cual Stark y Bloom (1985), infieren que el inmigrante no solo desea mejorar sus condiciones de vida, sino también las de su familia que se encuentra en su lugar de origen, 
Álvarez-Maldonado, David; Torres-Luque, Patricio; Letzkus-Palavecino, Manuel y

Araya-Castillo, Luis

Mapa de consenso del bienestar de inmigrantes en Lo Prado en Santiago de Chile

por lo tanto, migrar es una decisión familiar y no sólo personal.

Existen considerables diferencias de felicidad entre países, las cuales sugieren que la migración a otro país proporciona a muchas personas una importante oportunidad de obtener una vida más feliz. Sin embargo, las experiencias migratorias negativas son comunes, incluyendo la explotación ilegal, la exclusión social, la nostalgia y el fracaso de la asimilación socioeconómica (Mahler, 1995; Sayad, 2004; Mai, 2004).

\subsection{Bienestar y migración}

A nivel mundial, en 1990 existían 153 millones de personas viviendo fuera del país donde nacieron. En el año 2015 este número había aumentado a 244 millones. Existen estimaciones acerca de otros 700 millones de personas que les gustaría mudarse a otro país, pero aún no lo han hecho (Esipova, Ray y Pugliese, 2017).

En los países más desarrollados, la proporción de inmigrantes es muy alta. En Europa occidental, en algunos países equivale al $15 \%$ de la población, igual cifra alcanza en EE.UU., mientras en Canadá, Nueva Zelanda y Australia alcanza el 30\%. Los casos extremos se encuentran en los Emiratos Árabes Unidos y Kuwait, en donde la cifra alcanza el 70\% (Helliwell et al., 2018).

Al respecto de este cuestionamiento, se destaca el planteamiento de los autores Helliwell et al. (2018), los cuales caracterizaron el bienestar de los inmigrantes en función de los siguientes componentes: En el país receptor, los inmigrantes son casi tan felices como las personas locales; la felicidad de cada migrante depende no sólo de la felicidad de los lugareños, con una ponderación de aproximadamente 0,75 . También depende del nivel de felicidad en el país de origen del migrante, con una ponderación de aproximadamente 0,25 . Es decir, si un inmigrante emigra desde un país menos feliz a uno más feliz, de alguna manera terminará menos feliz que los locales. Por otra parte, lo contrario sucedería si emigra de un país más feliz a uno menos feliz; y, existe un factor tremendamente importante en la felicidad de los inmigrantes: El nivel de aceptación de las personas locales hacia los inmigrantes.

Desde otra perspectiva, según Hendriks (2015); y, Nikolova y Graham (2015), por lo general emigrar a un país más desarrollado produce una ganancia de felicidad y, por el contrario, emigrar a un país menos desarrollado generaría menos felicidad. Existen excepciones a este patrón: El caso de inmigrantes de Tonga hacia Nueva Zelanda investigado por Stillman et al. (2015); y de polacos a Europa occidental analizado por Bartram (2013). En ambos casos, luego de haber residido por algunos años en el extranjero, los inmigrantes se sentían menos felices que en sus países de origen. Aún más, existe evidencia que, en algunos países, la segunda generación de inmigrantes no es más feliz que la de sus padres según Safi (2010).

Una forma de explicar esto es con relación a grupos de referencia. Cuando el inmigrante emigra a una nación más feliz, su grupo de referencia de comparación es aún su país de origen, lo cual le hace más feliz. Mientras el tiempo pasa, el grupo de referencia pasa a ser el país de destino, lo cual le hace menos feliz. El mismo proceso continúa con la segunda generación.

En conclusión, y al comparar el nivel de felicidad de los inmigrantes con quienes se quedaron en su lugar de origen, Hendriks et al. (2018) señalan que los inmigrantes son un $9 \%$ más felices de lo que eran antes de emigrar, experimentando un 5\% más de afecto positivo debido a la inmigración.

Estos resultados implican que, a pesar de la ganancia de felicidad experimentada por una gran cantidad de inmigrantes, existe un importante grupo de inmigrantes internacionales quienes no experimentan un mayor nivel de felicidad. Lo anterior depende principalmente de la calidad de vida que experimentan en el país que los recibe, que ilustra un patrón general de convergencia: El estado de bienestar cambia de acuerdo con la calidad de la sociedad en que vive la gente, por lo que las autoridades políticas y los servicios 
públicos están relacionados (Gutiérrez et al., 2020).

La felicidad de los inmigrantes, como la de los nacidos localmente, depende de una serie de características del tejido social, que se extienden mucho más allá de los ingresos más altos, tradicionalmente pensado para inspirar y recompensar la migración. Las autoridades y los servicios públicos se ven desafiados por esta problemática, en el marco de los del respeto a los derechos humanos (Guillén, Menéndez y Moreira, 2019).

En la actualidad chilena, han surgido casos de racismo contra inmigrantes haitianos que realizan labores de limpieza en las calles, plazas de Santiago y otras ciudades. Según Tijoux (2017), la sociedad chilena desconoce la historia y cultura de los inmigrantes haitianos, sin pensar en el sufrimiento que padecen durante su estadía.

Los antecedentes y la evidencia documental, permiten sostener que el bienestar subjetivo de la población migrante cambia según la calidad de la sociedad en que se desarrolla, existiendo una particularidad posible de describir y representar, a la vez que una necesidad de caracterización de estos grupos contingentes, por parte de las autoridades locales encargadas de diseñar y gestionar servicios públicos para la población inmigrante, en el marco de los derechos humanos (Guillén et al., 2019; Gutiérrez et al., 2020; Berrios-Riquelme et al., 2021).

\section{Metodología}

La subjetividad de los inmigrantes, la cual orientan la acción de estos, puede ser ignorada por el aparato público y las autoridades locales si no accede a ellos mediante evidencias; a pesar de ser un grupo relativamente minoritario de la población, es información fundamental para el diseño de políticas públicas universales. Esta realidad subjetiva del inmigrante es de difícil acceso y no puede ser obtenida la información personal en profundidad adecuada, exclusivamente mediante técnicas cuantitativas como encuestas, dado que este segmento de población padece de diversas barreras lingüísticas y culturales para acceder a los procesos de socialización (Morosanu, 2013), invisibilizándose las percepciones y culturas en los que participan los individuos.

Este estudio está orientado desde una propuesta metodológica de enfoque cualitativo, basada en técnicas proyectivas usando imágenes (Zaltman, 2014; Wu, 2018), que pretende evidenciar las emociones de usuarios de servicios. Esta metodología accede a discursos significativos de las personas, permitiendo reconocer los modelos mentales de los sujetos (Liu y Liu, 2013), siendo estos elementos cognitivos fundamentales para la comprensión del pensamiento y comportamiento de las personas.

Este enfoque metodológico cualitativo permite conocer los modelos mentales de la gente y comprender el comportamiento de las personas (Christensen y Olson, 2002; Ling et al., 2009). Esta alternativa analítica puede ser adaptada al ámbito sociocultural ante el desafío metodológico de acceder a los contenidos emocionales implícitos en los discursos de los informantes inmigrantes, para comprender sus modelos mentales.

La orientación proyectiva basada en imágenes es clasificada como una alternativa no-tradicional para conocer lo que realmente quieren usuarios de servicios, mediante el abordaje de sus emociones, utilizando imágenes que representan el asunto a investigar; en el caso de este estudio, la visualización del estado de bienestar para las personas inmigrantes, formalizado en la pregunta: ¿Cuáles son las características del bienestar subjetivo de la población inmigrante que utiliza servicios municipales de la Comuna de Lo Prado de Santiago de Chile?

Los fundamentos que justifican esta propuesta metodológica de tipo proyectiva, son que los modelos mentales suceden mayormente basados en imágenes, que la comunicación es en alto porcentaje noverbal, y que en discursos de las personas se puede convocar emociones mediante técnicas gráficas (Coulter y Zaltman, 1994; Zaltman 
Álvarez-Maldonado, David; Torres-Luque, Patricio; Letzkus-Palavecino, Manuel y

Araya-Castillo, Luis

Mapa de consenso del bienestar de inmigrantes en Lo Prado en Santiago de Chile

y Coulter, 1995; Zaltman, 1996; 2014). Asimismo, la técnica implementada es una entrevista en profundidad semi-estructurada, en la cual se utilizan dibujos como estímulo a la conversación (Catchings-Castello, 2000), elaborados por los usuarios de forma previa.

El ámbito de reflexión se definió basado en las características de lo que se entiende por el estado de bienestar subjetivo, visto desde el inmigrante, siendo la muestra constituida por conveniencia según criterios de las autoridades del gobierno local, y del trabajo de campo realizado por funcionarios municipales con inmigrantes usuarios de servicios públicos, conformándose por doce informantes clave de la comuna de Lo Prado de Santiago de Chile, los cuales fueron seleccionados por red de contactos que funcionarios del gobierno local desarrollan en su trabajo de campo, de un universo contingente debido a la informalidad de la inmigración irregular y a la alta rotación de usuarios del servicio municipal.

Cada individuo participante de la entrevista dibujó previamente una cantidad de imágenes que representan su visión sobre la problemática abordada, la felicidad o bienestar subjetivo, pudiendo ser entre 6 a 8 unidades. El procedimiento consistió en la presentación de las imágenes, realizando una serie de pasos reflexivos que orientaron la estructura de la entrevista en profundidad. La técnica se compone de 8 pasos semiestructurados, los cuales fueron adaptados a los requerimientos de los informantes clave: La historia de cada imagen, las imágenes perdidas, descartar imágenes, provocación de constructos, distorsión de las imágenes, elaboración de una imagen sensorial, elaboración de un relato en viñetas, y finalmente elaboración de collage. A continuación, se describen en profundidad cada paso:

Paso 1: El participante debe contar la historia de cada dibujo que elaboró previamente a la entrevista, explicando sus motivos de crearlo o diseñarlo, lo que representa de forma exhaustiva, y distinguiéndola de los otros dibujos. Esta etapa es extensa, y se debe orientar al participante para que profundice en cada significado particular y su diferenciación de los otros significados.

Paso 2: El participante, junto al entrevistador, reflexiona sobre los dibujos que podrían haber sido elaborados pero que por diferentes motivos no se encuentran en la entrevista, denominándose imágenes perdidas. Posteriormente, pueden ser representadas gráficamente e incluidas en el set de imágenes seleccionadas, procediendo a explicar su significado diferenciado como en el Paso 1.

Paso 3: El participante, junto al entrevistador, reflexionan sobre las imágenes duplicadas y susceptibles de ser descartadas debido a la redundancia en lo que representan respecto de otros dibujos con igual significado o composición, seleccionando una que las represente y generalizando su sentido, así como descartando la que duplica el sentido.

Paso 4: Esta es la etapa de creación de constructos, es la que permite levantar información relevante para el análisis de los modelos mentales. Se deben seleccionar tres imágenes de forma azarosa, con la finalidad de entregar más control al participante, también se permitió que el participante puede crear agrupaciones de dos, tres, cuatro, cinco o seis imágenes, denominándolas con un título y describiendo a estos grupos o conjuntos, constituyendo constructos representativos de forma iterativa y diferenciada de las otras imágenes que quedan fuera de las agrupaciones, para permitirle mayor control de la entrevista y de las imágenes utilizadas.

Los participantes tienen la posibilidad de seleccionar las agrupaciones de imágenes, nombrarlas, describirlas y diferenciarlas de las otras imágenes fuera del conjunto. Estas categorías emergentes y sus diferencias con otras imágenes representativas de otras categorías, servirán de apoyo a la codificación del discurso en el análisis mediante el software NVivo. Es posible repetir esta tarea de agrupar y diferenciar las imágenes varias veces, desordenando y reordenando el set de imágenes, profundizando en cada conjunto configurado y que constituye un constructo con su nombre y sus explicaciones asociadas, así como sus diferencias con las otras imágenes y otros constructos elaborados. Se recomienda 
repetir la agrupación de imágenes, hasta alcanzar algún grado de saturación temática en que se repitan las categorías y sus significados, es decir, no se ocurran nuevos conjuntos.

Paso 5: El participante selecciona la imagen o las imágenes de mayor relevancia y más representativas hasta el momento de la entrevista, y se le aplican ejercicios de distorsión, por ejemplo, preguntar por lo que sucedió antes y lo que sucedió después de la imagen, o ampliar el cuadro ficticiamente y preguntar qué se encontraría en el entorno extendido. También se pueden realizar otros ejercicios de distorsión o expansión, con otras imágenes, por ejemplo, preguntar por el significado de la representación, y luego preguntar por su significado opuesto y la imagen asociada, aplicando nuevamente ejercicios de distorsión. Esta etapa es iterativa, así como exhaustiva, fundándose en la imagen más relevante, al igual que en otras imágenes que también sean importantes según el participante.

Paso 6: El entrevistador invita al participante a crear una imagen sensorial basada en la entrevista y temática de investigación, no visual, fundada en los sentidos como el tacto, el aroma, el sonido, el color o alguna emoción, que pueda desprender producto de la reflexión en la entrevista.

Paso 7: El entrevistador invita al participante a crear y relatar una breve historia que represente la temática en investigación y la conversación desarrollada hasta el momento, en cuadros, viñetas o escenas que estructuren el relato, pero en movimiento, por ejemplo, con inicio, desarrollo, conflicto y final.

Paso 8: Finalmente, el participante crea un collage o cuadro de conjunto de elementos ordenados aleatoriamente, con todas las imágenes de la entrevista, jerarquizándolas según relevancia, y explica de forma exhaustiva el significado del conjunto colocando un título representativo a una persona hipotética que no hubiera participado de la entrevista, con el objetivo de finalizar reflexionando sobre un posible modelo mental del individuo entrevistado, mediante la relación de constructos abordados en el cuadro recreado mediante los dibujos.

Los resultados de esta aplicación generaron discursos estimulados por dibujos, de los cuales se identificaron constructos representativos del modelo mental del individuo informante, susceptible de ser graficado en un diagrama conceptual. Posterior a la realización de la entrevista, el discurso del informante es almacenado en un registro de audio y transcrito a un documento de texto de forma rigurosa y realista, con el objetivo de analizarlo mediante el software NVivo en función de sus segmentos significativos que, utilizando metáforas, dieron cuenta de constructos y sus vínculos, creando una codificación emergente susceptible de interpretación, que fundamentará una gráfica en formato de red denominado mapa de consenso.

Los segmentos significativos fueron seleccionados y codificados mediante categorías emergentes de forma exhaustiva, generando una gran diversidad de constructos, presentes en mayor o menor medida en el conjunto de informantes. La forma de realizar esta operación consistió en seleccionar los segmentos agrupándolos en nodos significativos, los cuales después se analizaron en función de los traslapes. La matriz de codificación, permite observar la superposición o relación de las diferentes categorías utilizadas para segmentar, dado que cada dato puede referenciar a más de un código. Los discursos de los informantes fueron analizados de forma individual, para posteriormente, seleccionar las categorías clave y vínculos más significativos del conjunto de entrevistas, creando de esta forma un mapa consensuado respecto de lo que los inmigrantes visualizan sobre el estado de bienestar.

\section{Resultados y discusión}

La presente investigación logró sintetizar en un modelo de constructos tipo mapa, el consenso de diferentes e individuales modelos mentales presentes en la muestra de informantes clave. Este mapa de consenso 
permite representar la visualización desde el actor social denominado inmigrante sobre el estado de bienestar subjetivo.

El mecanismo de análisis de este mapa está sustentado en dos variables: Por un lado, los nodos o constructos conceptuales; y por otro, las relaciones entre constructos. Similar a un mapa geográfico con la delimitación de localidades y rutas, el mapa de consenso, permite ubicar conceptualmente la información, utilizándose de diferentes formas, según los intereses del análisis o, en función de la metáfora geográfica, destino del viaje.

Los elementos por destacar son los nodos o constructos con más relaciones, los cuales se vuelven variables clave al momento de pensar el bienestar subjetivo o felicidad de la población inmigrante, configurándose a veces como nodos iniciales o terminales, debido a la cantidad mayor de interrelaciones con otros nodos o su ubicación significativa en el mapa. También es necesario destacar los nodos de tránsito, los cuales, sin tener una gran cantidad de interrelaciones, están ubicados mediando otros nodos. Finalmente, las mismas relaciones permiten visualizar el movimiento del pensamiento de la población inmigrante respecto de sus cuestionamientos sobre su propia felicidad, posibilitando componer pensamientos más complejos, similar a las redes neuronales del sistema nervioso y sus conexiones.

En el mapa de consenso (ver Figura I), cada constructo delimitado y definido de forma particular, establece su rol en relación con los otros constructos, con el objetivo de conceptualizar los resultados de la indagación en el marco de modelos mentales específicos. Los factores comunes a los diferentes informantes clave, permiten comprender un modelo mental representativo a una diversidad de individuos involucrados en el levantamiento de información.

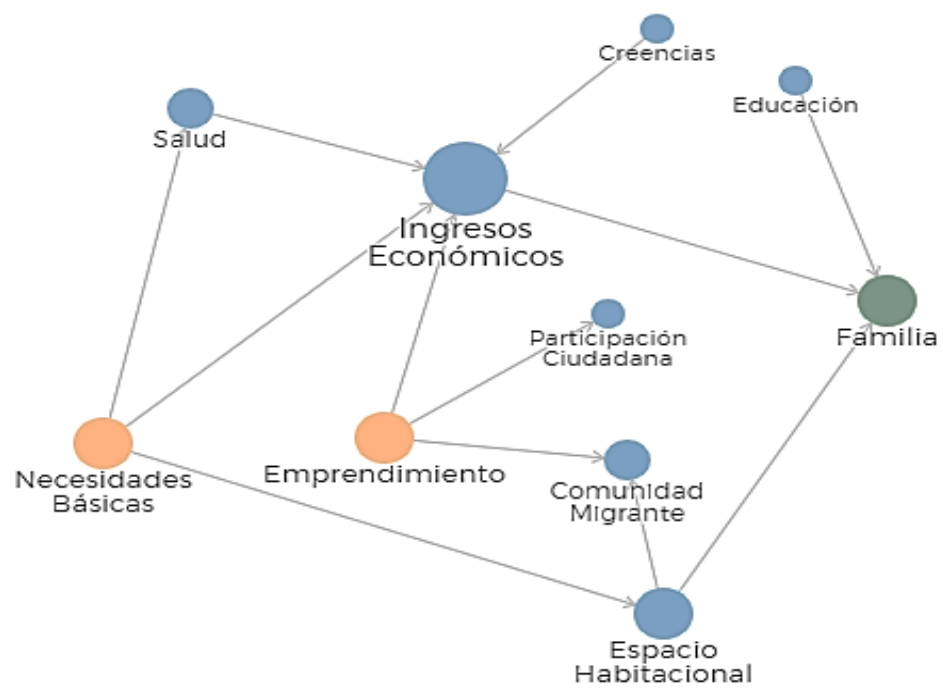

Fuente: Elaboración propia, 2021 mediante el software Nvivo

Figura I: Mapa de Consenso del inmigrante vulnerable de la comuna de Lo Prado, Santiago de Chile, sobre su estado de bienestar subjetivo 
En el marco de estos resultados, la definición de cada constructo surge del análisis cualitativo de los discursos presentes en las entrevistas y codificados mediante el software NVivo. A continuación, se operacionalizan los diferentes constructos representativos a la muestra seleccionada:

\subsection{Necesidades básicas}

Se expone la situación de carencias e insatisfacciones, por lo que son seres humanos en situaciones vulnerables o de mayores riesgos potenciales, que deben satisfacer necesidades básicas para encontrar el bienestar subjetivo o felicidad, lo que significa que padecen de requerimientos mínimos de subsistencia. Este ámbito se relaciona, coherentemente, con el constructo de salud, el de espacio habitacional y el de una fuente de ingresos económicos (ver Figura I). Se puede interpretar como un nodo inicial, que genera una apertura al cuestionarse sobre la felicidad u otro pensamiento representativo a esta problemática. Particularmente, la muestra señalaba que era una de sus preocupaciones fundamentales satisfacer las necesidades de su grupo familiar, y en relación con otros nodos, ocupa un rol de iniciar el movimiento.

\subsection{Salud}

Es una necesidad básica fundamental, considerada en el discurso de la muestra como requisito indispensable para obtener ingresos económicos, por lo que carecer de buena salud afecta los ingresos obtenidos. Es un nodo que media entre necesidades básicas e ingresos económicos, tal como se aprecia en la Figura I.

\subsection{Espacio habitacional}

Es un requerimiento de subsistencia, se relaciona con las necesidades básicas, mediando con la familia y también con la comunidad migrante, siendo la infraestructura para socializar con otros individuos miembros de su comunidad o gente cercana (ver Figura I). En los discursos de los informantes clave, se presentaba el espacio habitacional como un lugar de encuentro con otros de la misma comunidad inmigrante o familiar.

\subsection{Ingresos económicos}

Es un requerimiento de subsistencia básica, al igual que salud e infraestructura habitacional. Se constituye como un nodo relevante que interconecta varios nodos, relacionando o mediándolos con el nodo terminal que es la familia, tal como se evidencia en la Figura I. Es una necesidad que tiene como requisito la salud, y orienta gran parte de la conversación con los inmigrantes quienes participaron de las entrevistas.

\subsection{Emprendimiento}

Es un nodo inicial, la cual es una actividad de interés que permite obtener ingresos económicos mejores que los de empleos no calificados y participar de la sociedad como actor relevante ayudando a su comunidad en la creación de valor y empleos, tal como se puede apreciar en la Figura I. Se presenta como una visión ideal de los inmigrantes y fuente de soluciones en términos de ingresos económicos y participación social.

\subsection{Participación ciudadana}

Representa el interés por ser un aporte a la sociedad en que se vive, conviviendo de forma digna con los oriundos de la zona, y ser respetado en su diferencia como inmigrante. La posibilidad de obtener este logro de participación social es apoyada por el constructo denominado emprendimiento (ver Figura I), dado que esta actividad económica fomentaría la inserción social 
Álvarez-Maldonado, David; Torres-Luque, Patricio; Letzkus-Palavecino, Manuel y

Araya-Castillo, Luis

Mapa de consenso del bienestar de inmigrantes en Lo Prado en Santiago de Chile

y el empoderamiento comunitario de los inmigrantes.

\subsection{Comunidad migrante}

Es un nodo terminal del emprendimiento y el espacio habitacional, como se evidencia en la Figura I. Los pares comunitarios, otros inmigrantes, son visualizados como relevantes en la conformación de la sociedad y en la articulación de la propia vida con bienestar subjetivo. Los otros cercanos, como familiares o amistades, gente con la misma nacionalidad, son parte fundamental de la felicidad del inmigrante. Para el logro de una comunidad fortalecida, se requiere el apoyo de los nodos de emprendimiento y espacio habitacional, permitiendo estos constructos establecer la infraestructura básica para sostener la comunidad en términos territoriales $\mathrm{y}$ financieros.

\subsection{Creencias}

Es un nodo auxiliar que otorga protección y resistencia para perseverar en su búsqueda de sustento económico, apoyando el nodo de los ingresos (ver Figura I). Permite enfrentar adversidades, así como desarrollar una actitud de resiliencia. Este constructo está asociado a la fe religiosa institucionalizada o individual, considerándose como una respuesta ante las adversidades y situaciones de vulnerabilidad.

\subsection{Educación}

Es un nodo auxiliar (ver Figura I), que otorga felicidad a la familia debido a que establece dignidad y respeto, en el marco de la inclusión social, al obtener logros académicos que significan participación ciudadana y profesionalización de sus labores económicas, fortaleciendo su familia.

\subsection{Familia}

Es el nodo terminal del mapa mental, como se evidencia en la Figura I, todas las acciones confluyen en aportar ingresos y espacio habitacional a su familia. Es el constructo clave para entender la orientación del comportamiento del inmigrante. El destino del pensamiento y acción de esta población, es generar un aporte a su familia en términos de infraestructura, así como recursos económicos.

El presente análisis evidencia las características vulnerables del grupo de inmigrantes, los cuales necesitan resolver requerimientos vitales básicos para lograr un estado de bienestar. Esta situación de carestía es enfrentada desde una propuesta de emprendimiento comunitario que involucra a grupos familiares o migrantes, otorgándole un carácter social a su iniciativa económica y de bienestar, probablemente debido a las barreras culturales que enfrentan al migrar (Morosanu, 2013).

Los datos señalan, que el componente de vulnerabilidad es fundamental en el discurso de la muestra de informantes clave de la población inmigrante de la comuna de Lo Prado en Santiago de Chile, seleccionada por las autoridades del gobierno local en función del trabajo de campo de funcionarios de servicios públicos. A modo de comprensión global, el estudio de la vulnerabilidad se debe relacionar con características intrínsecas del sistema social, como disparidad económica, cesantía, rechazo social o incapacidad para enfrentar amenazas (Chambers, 1983; Birkmann, 2006; Cornado et al., 2017; Torres, 2019).

Esta limitación de las capacidades se relaciona con las carencias presentes en el mapa en los nodos: a) Necesidades básicas; b) ingresos económicos; c) espacio habitacional; y, d) salud; constituyéndose estos elementos como variables fundamentales del modelo mental consensuado de la muestra de informantes clave proporcionados por el gobierno local.

$$
\text { Anderson y Woodrow (1998), }
$$


precursores en el desarrollo de métodos prácticos de evaluación de la vulnerabilidad, como la presente en los discursos de los informantes investigados, describen a esta categoría como los componentes a largo plazo que inciden en la facultad de una colectividad para responder a eventos o problemas, lo que la hacen susceptible a las adversidades e infortunios, existiendo diversos tipos de vulnerabilidad (Alexander, 2013; Torres, 2019). En relación con el origen y causas de la vulnerabilidad social, la evidencia señala que los más importantes son aspectos sociales y económicos (Zanchetta et al., 2008; Pascal et al., 2009; Chaudry et al., 2010; Perez, 2011; Robert et al., 2014; Torres, 2019).

Por su parte, Kullgreen (2003); Snowden y Yamada (2005); así como Cabieses et al. (2017), señalan que las variadas barreras para acceder a servicios públicos amenazan el bienestar de la población migrante, en coincidencia con el mapa de consenso de la muestra de inmigrantes de Lo Prado, en el nodo de salud.

Respecto a la educación e integración de los niños inmigrantes, unos de los ejes representados en los nodos fueron: a) Participación ciudadana; b) educación; y, c) familia; según plantea Castillo, Santa-Cruz y Thayer (2019), la situación se caracteriza por un creciente arribo de inmigrantes al sistema escolar chileno, evidenciando la falta de políticas públicas para incorporarlos al sistema educativo; además, diferencias entre las familias migrantes y no migrantes, tales como: El proceso de inserción en el mercado laboral chileno, principalmente en trabajos no calificados, con bajos ingresos y pocos recursos materiales, como también culturales.

\section{Conclusiones}

El estado de bienestar subjetivo de la población migrante es un fenómeno contingente y multicausal, relacionado con el contexto social en que se desarrolla, el cual se configura como un desafío para el diseño pertinente de los servicios públicos, en el marco del respeto a los derechos humanos. En función de los antecedentes recopilados, es posible sostener que el estado de bienestar depende del contexto social modulado por servicios públicos, los cuales están orientados por los derechos humanos a ser pertinentes para la población inmigrante local.

En relación con el origen y causas de la vulnerabilidad social, se pudo evidenciar que los más significativos son los aspectos sociales, así como económicos. Asimismo, se encontró que las distintas barreras para acceder a los servicios públicos amenazan el bienestar de la población migrante, tal como se muestra en el mapa de consenso de la muestra de inmigrantes de Lo Prado, particularmente en el nodo de salud.

Con respecto a la educación e integración de los niños inmigrantes, se encontró que la misma se caracteriza por un incremento en la presencia de éstos al sistema escolar chileno, lo cual colocó en evidencia la falta de políticas públicas para incorporarlos al sistema educativo; mostrándose además, diferencias entre las familias migrantes y no migrantes, sobre todo en cuanto al proceso de inserción en el mercado laboral chileno, especialmente en trabajos no calificados, con bajos ingresos y pocos recursos materiales, así como culturales.

Finalmente, los resultados evidencian la centralidad de temáticas sobre la obtención de ingresos económicos, así como la satisfacción de necesidades básicas en el marco de actividades familiares, como también de emprendimiento. Por lo tanto, existen necesidades básicas no cubiertas asociadas a la relevancia de diseñar servicios públicos pertinentes, que contribuyan a incrementar el bienestar de los inmigrantes en Lo Prado en Santiago de Chile.

\section{Referencias bibliográficas} Adler, A. (2009). Gross national happiness
in Bhutan: A living example of an
alternative approach to progress. 
Álvarez-Maldonado, David; Torres-Luque, Patricio; Letzkus-Palavecino, Manuel y Araya-Castillo, Luis

Mapa de consenso del bienestar de inmigrantes en Lo Prado en Santiago de Chile

Wharton Research Scholars Journal.

Alexander, D. (2013). Vulnerability. In K. Penuel, M. Statler y R. Hagen (Eds.), Encyclopedia of crisis management (pp. 980-983). SAGE.

Anderson, M. B., y Woodrow, P. J. (1998). Rising from the ashes: Development strategies in time of disaster. Lynne Rienner Publishers.

Bartram, D. (2013). Happiness and 'economic migration': A comparison of eastern European migrants and stayers. Migration Studies, 1(2), 156-175. https://doi.org/10.1093/migration/ mnt006

Berrios-Riquelme, J., Ventura-León, J., Maluenda-Albornoz, J., y BarbozaPalomino, M. (2021). Propiedades psicométricas de la escala de amenaza grupal internalizada por inmigrantes latinoamericanos en Chile. Revista de Ciencias Sociales (Ve), XXVII(2), 467-483. https://doi.org/10.31876/rcs. v27i2.35935

Berry, J. W. (2006). Acculturative stress. In P. T. P. Wong y L. C. J. Wong (Eds.), Handbook of multicultural perspectives on stress and coping (pp. 287-298). Spring Publications. https:// doi.org/10.1007/0-387-26238-5 12

Birkman, J. (2006). Measuring vulnerability to promote disaster-resilient societies: Conceptual framework and definitions. In J. Birkmann (Ed.), Measuring vulnerability to natural hazards: Towards disaster resilient societies (pp. 9-54). United Nations University Press.

Cabieses, B., Chepo, M., Oyarte, M., Markkula, N., Bustos, P., Pedrero, V., y Delgado, I. (2017). Health inequality gap in immigrants versus local children in Chile. Revista Chilena de Pediatría, 88(6), 707716. http://dx.doi.org/10.4067/S0370-

\section{7}

Castillo, D., Santa-Cruz, E., y Thayer, E. (2019). Estudiantes migrantes en escuelas públicas chilenas. Editorial Aún creemos en los sueños.

Catchings-Castello, G. (2000). The Zmet alternative. A nontraditional, multidisciplinary technique lets marketing researchers analyze what customers want. Marketing Research, $12,6-12$.

Chambers, R. (1983). Rural development: Putting the last first. Routledge.

Chaudry, A., Capps, R., Pedroza, J. M., Castañeda, R. M., Santos, R., y Scott, M. M. (2010). Facing our future children in the aftermath of immigration enforcement. The Urban Institute.

Christensen, G. L., y Olson, J. C. (2002). Mapping consumers' mental models with ZMET. Psychology \& Marketing, 19(6), 477-502. https://doi. org/10.1002/mar.10021

Cornado, C., García-Almiralli, M., Vilma, S., Vilá, G., y Uzqueda, A. (2017). Methodology for the Detection of Residential Vulnerable Areas - the Case of Barcelona. IOP Conference Series: Materials Science and Engineering, 245, 042062. https://doi.org/10.1088/1757$\underline{899 X / 245 / 4 / 042062}$

Coulter, R. H., y Zaltman, G. (1994). Using the Zaltman metaphor elicitation technique to understand brand images. In C. T. Allen y D. Roedder (Eds.), NA - Advances in Consumer Research Volume 21 (pp. 501-507)._Association for Consumer Research

Easterlin, R. A. (1974). Does economic growth improve the human lot? Some empirical evidence. In P. A. David y M. W. Reder (Eds.), Nations and households in economic growth: 
Essays in honor of Moses Abramowitz (pp. 89-125). Academic Press, Inc. https://doi.org/10.1016/B978-0-12205050-3.50008-7

Esipova, N., Ray, J., y Pugliese, A. (June 8, 2017). Number of potential migrants worldwide tops 700 million. Gallup. https://news.gallup.com/poll/211883/ number-potential-migrantsworldwide-tops-700-million.aspx

Frey, B. S., y Stutzer, A. (2014). Economic consequences of mispredicting utility. Journal of Happiness Studies, 15(4), 937-956. $\quad$ https://doi.org/10.1007/ s10902-013-9457-4

Ghorra-Gobin, C. (Dir.) (2006). Dictionnaire des mondialisations. Armand Colin.

Graham, C. (2005). The economics of happiness. World Economics, 6(3), 41-55.

Guillén, J. C., Menéndez, F. G., y Moreira, T. K. (2019). Migración: Como fenómeno social vulnerable y salvaguarda de los derechos humanos. Revista de Ciencias Sociales (Ve), XXV(1), 281294.

Gutiérrez, J. M., Romero, J., Arias, S. R., y Briones, X. F. (2020). Migración: Contexto, impacto y desafío. Una reflexión teórica. Revista de Ciencias Sociales (Ve), XXVI(2), 299313. $\quad$ https://doi.org/10.31876/rcs. v26i2.32443

Helliwell, J., Layard, R., y Sachs, J. (Eds.) (2012). World happiness report 2012. UN Sustainable Development Solutions Network. https:// s3.amazonaws.com/happinessreport/2012/World_Happiness Report_2012.pdf

Helliwell, J., Layard, R., y Sachs, J. (Eds.) (2015). World happiness report 2015. Sustainable Development Solutions Network. https://s3.amazonaws.com/ happiness-report/2015/WHR15

\section{$\underline{\text { Sep15.pdf }}$}

Helliwell, J., Layard, R., y Sachs, J. (Eds.) (2018). World happiness report 2018. Sustainable Development Solutions Network. https://s3.amazonaws.com/ happiness-report/2018/WHR_web.pdf

Helliwell, J., Layard, R., y Sachs, J. (Eds.) (2019). World happiness report 2019. Sustainable Development Solutions Network. https://s3.amazonaws.com/ happiness-report/2019/WHR19.pdf

Helliwell, J., Layard, R., y Sachs, J. (Eds.) (2020). World happiness report 2020. Sustainable Development Solutions Network. https://happiness-report. s3.amazonaws.com/2020/WHR20.pdf

Hendriks, M. (2015). The happiness of international migrants: A review of research findings. Migration Studies, 3(3), 343-369. https://doi.org/10.1093/ migration/mnu053

Hendriks, M., Burger, M., Ray J., y Esipova, N. (2018). Do international migrants increase their happiness and that of their families by migrating. In J. Helliwell, R. Layard y J. Sachs (Eds.), World happiness report 2018 (pp. 44-65). Sustainable Development Solutions Network.

Kullgreen, J. T. (2003). Restrictions on undocumented immigrants' access to health services: the public health implications of welfare reform. American Journal of Public Health, 93(10), 1630-1633. https://doi. org/10.2105/ajph.93.10.1630

Ling, I-L., Yang, C-M., Liu, Y-F., y Tsai, Y-H. (2009). Penetrating adolescents' mental models of mp3 with ZMET. Adolescence, 44(176), 948-963.

Liu, M-T., y Liu, K-T. (2013). Consensus model of click-through thoughts of web surfers. Asia Pacific Management Review, 18(2), 161-180. https://doi. org/10.6126/APMR.2013.18.2.03 
Álvarez-Maldonado, David; Torres-Luque, Patricio; Letzkus-Palavecino, Manuel y Araya-Castillo, Luis

Mapa de consenso del bienestar de inmigrantes en Lo Prado en Santiago de Chile

Lyubomirsky, S., King, L., y Diener, E. (2005). The benefits of frequent positive affect: Does happiness lead to success? Psychological Bulletin, 131(6), 803855. https://doi.org/10.1037/0033$\underline{2909.131 .6 .803}$

Mahler, S. J. (1995). American dreaming: Immigrant life on the margins. Princeton University Press.

Mai, N. (2004). Looking for a more modern life: The role of Italian television in the Albanian migration to Italy. Westminster Papers in Communication and Culture, 1(1), 3-22. https://doi. org/10.16997/wpcc. 200

Minkov, M., y Bond, M. H. (2017). A genetic component to national differences in happiness. Journal of Happiness Studies, 18, 321-340. https://doi. org/10.1007/s10902-015-9712-y

Morosanu, L. (2013). Between fragmented ties and 'soul friendships': The crossborder social connections of young Romanians in London. Journal of Ethnic and Migration Studies, 39(3), 353-337. https://doi.org/10.1080/1369 $\underline{183 X .2013 .733858}$

Nikolova, M., y Graham, C. (2015). In transit: The well-being of migrants from transition and post-transition countries. Journal of Economic Behavior \& Organization, 112(C), 164-186. https://doi.org/10.1016/j. jebo.2015.02.003

Oishi, S., y Schimmack, U. (2010). Residential mobility, well-being, and mortality. Journal of Personality and Social Psychology, 98(6), 980-994. https:// doi.org/10.1037/a0019389

Organisation for Economic Co-operation and Development - OECD (2013). OECD guidelines on measuring subjective well-being. OECD Publishing. https:// doi.org/10.1787/9789264191655-en

Ottonelli, V., y Torresi, T. (2013). When is 400 migration voluntary? International Migration Review, 47(4), 783-813. https://doi.org/10.1111/imre.12048

Pascal, J., Abbey-Huguenin, H., Leux, C., Lombrail, P., y Lert, F. (2009). Social vulnerability and unmet preventive care needs in outpatients of two French public hospitals. European Journal of Public Health, 19(4), 403-411. https:// doi.org/10.1093/eurpub/ckp033

Perez, J. (2011). A Middle-class journeys: A comparative study of the residential and housing outcomes of Caribbean Latino, Black, and White native New Yorkers $[\mathrm{PhD}$ dissertation, Fordham University]. https://www.proquest. com/docview/866658455

Ratha, D., Eigen-Zucchi, C., y Plaza, S. (2016). Migration and remittances Factbook 2016. World Bank Publications. https://openknowledge. worldbank.org/bitstream/hand le/10986/23743/9781464803192.pdf

Robert, G., Martínez, J. M., García, A. M., Benavides, F. G., y Ronda, E. (2014). From the boom to the crisis: Changes in employment conditions of immigrants in Spain and their effects on mental health. European Journal of Public Health, 24(3), 404-409. https:// doi.org/10.1093/eurpub/cku020

Safi, M. (2010). Immigrants' life satisfaction in Europe: Between assimilation and discrimination. European Sociological Review, 26(2), 159-176. https://doi. org/10.1093/esr/jcp013

Sánchez, A. (2006). Crecimiento económico, desigualdad y pobreza: Una reflexión a partir de Kuznets. Problemas del Desarrollo, 37(145), 11-30.

Sayad, A. (2004). The suffering of the immigrant. Polity Press.

Snowden, L. R., y Yamada, A-M. (2005). Cultural differences in access to care. Annual Review of Clinical Psychology, 
1, 143-166. https://doi.org/10.1146/ annurev.clinpsy.1.102803.143846

Stark, O., y Bloom, D. E. (1985). The new economics of labor migration. American Economic Review, 75(2), 173-178.

Stillman, S., Gibson, J., McKenzie, D., y Rohorua, H. (2015). Miserable migrants? Natural experiment evidence on international migration and objective and subjective wellbeing. World Development, 65 , 79-93. https://doi.org/10.1016/j. worlddev.2013.07.003

Tijoux, M. E. (2017). Inmigrantes y racismo en Chile. En Le monde diplomatique (Ed.), Inmigrantes y refugiados: En Chile y el mundo. Editorial aún creemos en los sueños.

Torres, P. (2019). Precarización del capital humano en la ciudad de Santiago de Chile. El caso del voluntariado en albergues turísticos y hostales. Trilogía (Santiago), 31(42), 68-80.

Ucak, A. (2015). Adam Smith: The inspirer of modern growth theories. Procedia Social and Behavioral Sciences, 195, 663-672. https://doi.org/10.1016/j. $\underline{\text { sbspro.2015.06.258 }}$

United Nations - UN (2011). Happiness:
Towards a holistic approach to development. Resolution 65/309 adopted by the General Assembly. UN. https://digitallibrary.un.org/ record/715187

Wu,P.C.(2018). Seeing the voice of Taiwanese cuisine: Chinese University students' perspective. ICIC Express Letters, Part B: Applications, 9(5), 405-411.

Zaltman, G. (1996). Metaphorically speaking. New technique uses multidisciplinary ideas to improve qualitative research. Marketing Research, 8(2), 13-20.

Zaltman, G. (2014). Are You Mistaking Facts for Insights? Journal of Advertising Research, 54(4), 373-376. https://doi. org/10.2501/JAR-54-4-373-376

Zaltman, G., y Coulter, R. H. (1995). Seeing de voice of the customer: Methaporbased advertising research. Journal of Advertising Research, 35(4), 34-51.

Zanchetta, M. S., McCrae, S., Galhego-Garcia, W., Smolentzov, V. M. N., Talbot, Y., Riutort, M., Galhego, A. M. M. F., De Souza, T. J., Caldas, R. S., Costa, E., Kamikihara, M. M., y Smolentzov, S. (2008). Effectiveness of community health agents' actions in situations of social vulnerability. Health Education Research, 24(2), 330-342. https://doi. org $/ 10.1093 /$ her $/$ cyn023 